\title{
Perfusion-induced acute kidney injury: A litany of uncertainty and frustration
}

\author{
Victor A. Ferraris, MD, PhD

\footnotetext{
From the Division of Cardiothoracic Surgery, Department of Surgery, University of Kentucky, Kentucky Clinic, Lexington, Ky.

Disclosures: Author has nothing to disclose with regard to commercial support.

Received for publication April 19, 2018; accepted for publication April 19, 2018; available ahead of print May 18, 2018.

Address for reprints: Victor A. Ferraris, MD, PhD, Department of Surgery, University of Kentucky, A301 Kentucky Clinic, 740 S Limestone, Lexington, KY 40506-0284 (E-mail: ferraris@uky.edu).

J Thorac Cardiovasc Surg 2018;156:1928-30

$0022-5223 / \$ 36.00$

Copyright $(2) 2018$ by The American Association for Thoracic Surgery

https://doi.org/10.1016/j.jtcvs.2018.04.091
}

Litany is defined as a "tedious recital or repetitive series," and synonyms include "a lengthy enumeration or a sizable series of trials." This seems to be an appropriate word to describe investigations of acute kidney injury (AKI) after cardiopulmonary bypass (CPB). Just within the last year, there have been publications almost too numerous to count related to AKI and CPB. Table 1 gives a partial list of these publications that address mechanisms and interventions aimed at discovering causes and reducing incidence of postoperative AKI after CPB. It is symptomatic of the diversity and confusion surrounding AKI and CPB that published reports suggest that 3 of the interventions listed in Table 1 (atrial natriuretic peptide, remote ischemic preconditioning, and diuretic therapy) have opposite effects on AKI incidence after CPB. The article by Ranucci and coauthors $^{24}$ published in this issue of the Journal undoubtedly adds to this litany, and probably adds to the frustration as well. ${ }^{24}$

One of the factors that may affect this litany of uncertainty and frustration is the heterogeneity (substitute "confusion") surrounding the definition of AKI, especially after CPB. Expert panels propose at least 3 different consensus criteria on AKI, each with its own idiosyncrasies and with its own acronym (RIFLE [Risk, Injury, Failure, Loss of kidney function, and End-stage kidney disease], AKIN [Acute Kidney Injury Network], and KDIGO [Kidney Disease: Improving Global Outcomes]). Despite efforts at standardization, multiple AKI definitions continue to be used in clinical trials. Further problems arise in investigation of AKI after CPB because of end point definitions. ${ }^{25}$ There is always a trade-off in defining testable outcomes with either high clinical relevance or high event rates. There are strict outcome measures, such as renal replacement therapy after CPB, and liberal outcome measures, such as serum creatinine elevations. More liberal end points often surface in smaller trials, whereas strict end points are common in larger studies.

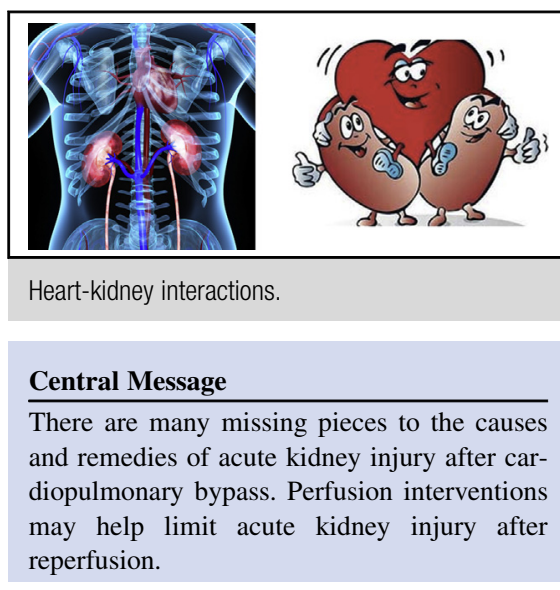

See Article page 1918.

Ranucci and coauthors ${ }^{24}$ have included some difficult choices in their study design. They were interested in the effect of increasing oxygen delivery on postoperative AKI. They chose to use the AKIN algorithm as one measure of post-CPB AKI. This algorithm relies on measures of serum creatinine and urinary output to create 3 categories of AKI with increasing levels of creatinine and decreasing levels of urine output (AKIN groups 1 through 3). For assessment of postoperative AKI, Ranucci and coauthors ${ }^{24}$ refined the AKIN outcome definitions into 2 subgroups by combining AKIN groups 2 and 3. This compromise in the outcome measures undoubtedly relates to their relatively small sample size and the infrequency of advanced AKI, as represented by AKIN levels 2 and 3, in the study group. Ranucci and coauthors ${ }^{24}$ developed a randomized trial that used what they call "goal-directed perfusion" (GDP) in the treatment arm, with the aim of maintaining oxygen delivery $\left(\mathrm{DO}_{2}\right)$ at greater than $280 \mathrm{~mL} \cdot \mathrm{min}^{-1} \cdot \mathrm{m}^{-2}$. They found a significant improvement in the AKIN level 1 group but not in the AKIN level 2 and 3 group when maintaining $\mathrm{DO}_{2}$ in the target range. Importantly, the only group with GDPrelated benefit was the group with the least significant AKI (AKIN stage 1). Patients with stage 2 or 3 AKIN did not have any benefit from GDP. There were very few patients with stage 2 or 3 AKI in the study group, however, and this limited sample size makes it very likely that there is a type 2 error in the assessment of this negative finding. Because of this limited sample size of patients with stages 2 and 3 of renal dysfunction, it is not appropriate to suggest that GDP has no effect on AKI in AKIN groups 2 and 3. The 
TABLE 1. Literature reports on interventions that limit acute kidney injury during cardiopulmonary bypass, from a brief review of articles published in 2017

Things that may reduce AKI after $\mathrm{CPB}$

- High HDL may improve AKI rates ${ }^{1}$

- Prophylactic furosemide infusions during and after CPB improve AKI rates

- Dexmedetomidine during CPB improves AKI rates

- Peritoneal dialysis in children ${ }^{4}$

- Optimization of KDIGO "bundle" (reduce hyperglycemia, optimize hemodynamics, avoid nephrotoxic drugs)

- Atrial natriuretic peptide

- Remote ischemic preconditioning during $\mathrm{CPB}^{7,8}$

Things that worsen AKI rates after CPB

- Hydroxyethyl starch prime may worsen

- Transfusion of red blood cells increases risk of $\mathrm{AKI}^{10}$

Things that did not affect AKI after CPB

- Ascorbic acid ${ }^{11}$

- Levosimendan ${ }^{12}$

- Bicarbonate ${ }^{13}$

- Remote ischemic preconditioning ${ }^{14-16}$

- Atrial natriuretic peptide

- Preoperative $\beta$-blocker ${ }^{18}$

- Allogeneic mesenchymal stem cells ${ }^{19}$

- Statin therapy ${ }^{20}$

- Spironolactone after $\mathrm{CPB}^{2}$

Things proposed but not tested

- Small interfering RNA ${ }^{22}$

- Hyperoxygenation during $\mathrm{CPB}$

$\overline{A K I \text {, Acute kidney injury; } C P B \text {, cardiopulmonary bypass; } H D L \text {, high-density lipopro- }}$ tein; KDIGO, Kidney Disease: Improving Global Outcomes.

statistical power of this negative observation is quite low, and it is likely that this negative observation is not meaningful. Further research with a larger study group is therefore necessary to make meaningful observations about patients who have AKIN level 2 or 3 renal dysfunction develop after CPB.

It is possible that the significant impact of optimizing $\mathrm{DO}_{2}$ during $\mathrm{CPB}$ on post-CPB AKI underestimates the true relationship between $\mathrm{DO}_{2}$ and AKI. One of the means of optimizing $\mathrm{DO}_{2}$ is to transfuse red blood cells during CPB. Some studies, however, suggest that this type of transfusion may actually increase the risk of AKI. ${ }^{10}$ Transfusion and GDP thus may represent a competing risk/ benefit relationship, with transfusion fostering AKI while GDP limits AKI, at least in the most common subgroup of patients with AKIN 1 level AKI. Much more work needs to be done to define the importance of perfusionrelated interventions in alleviating post-CPB AKI. Ranucci and coworkers ${ }^{24}$ have attempted to tackle a difficult problem with the science of a randomized trial, but there are still more questions than answers about the relationship between CPB and AKI. The frustration and uncertainty of postoperative AKI persists even in the face of this randomized trial.

\section{References}

1. Smith LE, Smith DK, Blume JD, Linton MF, Billings FT IV. High-density lipoprotein cholesterol concentration and acute kidney injury after cardiac surgery. $J$ Am Heart Assoc. 2017;6.

2. Fakhari S, Bavil FM, Bilehjani E, Abolhasani S, Mirinazhad M, Naghipour B. Prophylactic furosemide infusion decreasing early major postoperative renal dysfunction in on-pump adult cardiac surgery: a randomized clinical trial. Res Rep Urol. 2017;9:5-13.

3. Jo YY, Kim JY, Lee JY, Choi CH, Chang YJ, Kwak HJ. The effect of intraoperative dexmedetomidine on acute kidney injury after pediatric congenital heart surgery: a prospective randomized trial. Medicine. 2017;96:e7480.

4. Kwiatkowski DM, Goldstein SL, Cooper DS, Nelson DP, Morales DL, Krawczeski CD. Peritoneal dialysis vs furosemide for prevention of fluid overload in infants after cardiac surgery: a randomized clinical trial. JAMA Pediatr. 2017; 171:357-64.

5. Meersch M, Schmidt C, Hoffmeier A, Van Aken H, Wempe C, Gerss J, et al. Prevention of cardiac surgery-associated AKI by implementing the KDIGO guidelines in high risk patients identified by biomarkers: the PrevAKI randomized controlled trial. Intensive Care Med. 2017;43:1551-61.

6. Moriyama T, Hagihara S, Shiramomo T, Nagaoka M, Iwakawa S, Kanmura Y The protective effect of human atrial natriuretic peptide on renal damage during cardiac surgery. J Anesth. 2017;31:163-9.

7. Yi B, Chen X, Shi H, Lin T, Lin H, Xu Y, et al. Remote ischaemic preconditioning reduces acute kidney injury in adult patients undergoing cardiac surgery with cardiopulmonary bypass: a meta-analysis. Eur J Cardiothorac Surg. 2017;51: 616-23.

8. Zagidullin NS, Dunayeva AR, Plechev VV, Gilmanov AZ, Zagidullin SZ, Er F et al. Nephroprotective effects of remote ischemic preconditioning in coronary angiography. Clin Hemorheol Microcirc. 2017;65:299-307.

9. Svendsen ØS, Farstad M, Mongstad A, Haaverstad R, Husby P, Kvalheim VL. Is the use of hydroxyethyl starch as priming solution during cardiac surgery advisable? A randomized, single-center trial. Perfusion. 2017. 267659117746235.

10. Engoren M, Brown RR, Dubovoy A. A retrospective analysis of the effect of blood transfusion on cerebral oximetry entropy and acute kidney injury. Perfusion. 2017;32:35-43

11. Antonic M. Effect of ascorbic acid on postoperative acute kidney injury in coronary artery bypass graft patients: a pilot study. Heart Surg Forum. 2017;20: E214-8.

12. Putzu A, Clivio S, Belletti A, Cassina T. Perioperative levosimendan in cardiac surgery: a systematic review with meta-analysis and trial sequential analysis Int J Cardiol. 2018;251:22-31.

13. Cho JS, Soh S, Shim JK, Kang S, Choi H, Kwak YL. Effect of perioperative sodium bicarbonate administration on renal function following cardiac surgery for infective endocarditis: a randomized, placebo-controlled trial. Crit Care. 2017; $21: 3$.

14. Giannopoulos G, Vrachatis DA, Panagopoulou V, Vavuranakis M, Cleman MW Deftereos S. Remote ischemic conditioning and renal protection. J Cardiovasc Pharmacol Ther. 2017;22:321-9.

15. Kahlert P, Hildebrandt HA, Patsalis PC, Al-Rashid F, Jánosi RA, Nensa F, et al. No protection of heart, kidneys and brain by remote ischemic preconditioning before transfemoral transcatheter aortic valve implantation: interim-analysis of a randomized single-blinded, placebo-controlled, single-center trial. Int J Cardiol. 2017;231:248-54.

16. Menting TP, Wever KE, Ozdemir-van Brunschot DM, Van der Vliet DJ, Rovers MM, Warle MC. Ischaemic preconditioning for the reduction of renal ischaemia reperfusion injury. Cochrane Database Syst Rev. 2017;3: CD010777.

17. Mitaka C, Ohnuma T, Murayama T, Kunimoto F, Nagashima M, Takei T, et al Effects of low-dose atrial natriuretic peptide infusion on cardiac surgeryassociated acute kidney injury: a multicenter randomized controlled trial. $J$ Crit Care. 2017;38:253-8.

18. O’Neal JB, Billings FT IV, Liu X, Shotwell MS, Liang Y, Shah AS, et al. Effect of preoperative beta-blocker use on outcomes following cardiac surgery. Am J Cardiol. 2017;120:1293-7.

19. Swaminathan M, Stafford-Smith M, Chertow GM, Warnock DG, Paragamian V Brenner RM, et al; ACT-AKI investigators. Allogeneic mesenchymal stem cells for treatment of AKI after cardiac surgery. J Am Soc Nephrol. 2018;29:260-7.

20. Zhao BC, Shen P, Liu KX. Perioperative statins do not prevent acute kidney injury after cardiac surgery: a meta-analysis of randomized controlled trials. $J$ Cardiothorac Vasc Anesth. 2017;31:2086-92. 
21. Barba-Navarro R, Tapia-Silva M, Garza-Garcia C, López-Giacoman S, MelgozaToral I, Vázquez-Rangel A, et al. The effect of spironolactone on acute kidney injury after cardiac surgery: a randomized, placebo-controlled trial. Am J Kidney Dis. 2017;69:192-9.

22. Demirjian S, Ailawadi G, Polinsky M, Bitran D, Silberman S, Shernan SK, et al. Safety and tolerability study of an intravenously administered small interfering ribonucleic acid (siRNA) post on-pump cardiothoracic surgery in patients at risk of acute kidney injury. Kidney Int Rep. 2017;2:836-43.
23. Lopez MG, Pretorius M, Shotwell MS, Deegan R, Eagle SS, Bennett JM, et al. The risk of oxygen during cardiac surgery (ROCS) trial: study protocol for a randomized clinical trial. Trials. 2017;18:295.

24. Ranucci M, Johnson I, Willcox T, Baker RA, Boer C, Baumann A, et al. Goaldirected perfusion to reduce acute kidney injury: a randomized trial. J Thorac Cardiovasc Surg. 2018;156:1918-27.

25. Leaf DE, Waikar SS. End points for clinical trials in acute kidney injury. Am J Kidney Dis. 2017;69:108-16. 